Van der Merwe IJ \& Bekker $S$

\title{
URBANIZATION: AN INTERDISCIPLINARY APPROACH TO A COMPLEX PHENOMENON
}

Prof Izak van der Merwe, Department of Geography and Prof Simon Bekker, Department of Sociology, University of Stellenbosch.

\begin{abstract}
On account of the complexity and universal character of the urbanisation process, many academic disciplines, including Social Work, focus on this phenomenon. Accordingly, definitions tend to diverge, while the key concepts and research methodologies of the various disciplines are typically at variance with one another. Such a situation makes interdisciplinary and comparative international studies on urbanisation challenging to execute. One such comparative study has been initiated by the University of Stellenbosch, South Africa, and Bordeaux, France, promoting both interdisciplinary as well as intercontinental co-operation. The potential success of this interdisciplinary analysis arises mainly from the openness of concepts and methodologies as well as the judicious choice of cities. In addition, the selection of central questions and of shared themes appears to be important
\end{abstract}

This paper will reflect on these issues by considering aspects of a recently launched interdisciplinary and international research programme. Some perspective, however, is needed beforehand on the two relevant concepts of interdisciplinarity and urbanisation.

\section{INTERDISCIPLINARITY}

Knowledge is extracted from a fully integrated world. Knowledge is "disintegrated" by disciplinary units called departments in universities. How can knowledge, discovery and dissemination be re-integrated? (Caruso \& Rhoten, 2001)

For most of the twentieth century the question of knowledge has been framed by disciplinarity, but in recent decades a different view has emerged. Research is becoming increasingly interdisciplinary. New social and cognitive forms have altered the academic landscape, new practices have emerged, and disciplinary relations have been realigned (Weingart \& Stehr, 2000). There has, however, been very little focused inquiry regarding the components and factors that drive interdisciplinary research projects to success or failure (Caruso \& Rhoten, 2001). While the potential for "being interdisciplinary" is enormous, the reality is that few researchers have the confidence or the tools to approach a problem using interdisciplinary methods - even given the ubiquity of global networks which now allow researchers to connect, rather than protect, the knowledge they produce. As disciplines become more diffuse, their boundaries become blurred, and the number of new fields and specialities is growing by the day. In the face of an estimated 9000 distinguishable fields of knowledge, the promise of a reductionist unified science is not credible. Thus, interdisciplinarity has become a more pragmatic and realistic option (Weingart \& Stehr, 2000). It should be kept in mind that the boundaries between disciplines have become much more vague in recent times - the uniqueness of a scientific discipline is rooted in its core, not on its periphery.

Interdisciplinarity integrates separate disciplinary theories, concepts, skills, data and methodologies to bear on a common problem with a hybrid character. Interdisciplinary research properly conducted can increase the explanatory power, the immediate relevance, and the practical 
applicability of research to solve complex, real-world problems. However, few researchers or institutions have meaningful experience in its true practice. The reason for such a paradox is that the practice of interdisciplinarity is difficult and fraught with obstacles, particularly for researchers who have been raised and who continue to participate in the tradition of disciplinarity and departmentalism (Caruso \& Rhoten, 2001). These barriers, according to Pellmor and Eisenberg (2000), present themselves in five categories: researchers' attitudinal resistance, communication barriers among disciplines, departmental structures in academe, funding problems and career opportunities.

While disciplinary research is, and will remain, vitally important, broader approaches of interdisciplinarity, multidisciplinarity and transdisciplinarity are needed to focus on the increasingly integrated problems and issues of today's complex world. Synthesis and specialisation will have to operate in co-existence.

If interdisciplinary research is so important then, why isn't everyone doing it? This is probably because interdisciplinarity goes against the grain of everything disciplinary academics have been taught to do and to protect. The difference between the two perspectives is significant. For example, from the perspective of an interdisciplinarian, disciplines are rigid, conservative and averse to innovation. But from the disciplinary perspective, interdisciplinary research is vague and speculative. If synthesis and specialisation must learn to co-exist, then more researchers must actually start making this happen.

The "unity of knowledge" concept initiated significant interdisciplinary programmes in various subject areas and universities. Several themes lend themselves more specifically to interdisciplinary research. A few specific themes are: biodiversity, ecosystems, environmentalism, globalisation, information systems, social well being and urbanization. It is the last-mentioned focus that our international research group at Stellenbosch University is in the process of operationalising an interdisciplinary programme on comparative global urbanization. In South Africa the National Research Foundation's nine focus areas are also an indication of this interdisciplinary approach (NRF, 2000).

\section{URBANISATION}

The concept of urbanisation appears in the literature of nearly every social science (Kuper \& Kuper, 1996). Within each one it is used loosely when the theories of the particular field are applied to the study of urban units and their populations. The term does, however, have two interrelated core meanings. First, it refers to the redistribution of population between rural and urban areas. Second, in a number of social sciences - most notably Management and Political Sciences, Economics, Geography, Social Work and Sociology - urbanisation refers to the morphological and administrative configuration, the socio-economic structures, the human behavioural patterns and the transformation of urban agglomerations. Various attributes of the population and related social, economic and political dimensions are associated with urban living; as a consequence, the separate subfields of Urban Sociology, Urban Politics, Urban Economics and Urban Geography have become important components of the social sciences (Johnston et al., 2000).

In an attempt to launch discussion and research on city comparison in an interdisciplinary way, a common platform was offered by the declaration and action plan formulated at a major global conference in Berlin in 2000 on the urban future in the 21 st century. The outcomes of this United Nations conference - which I attended - focused on this declaration and the action plan. 
The World Report on the Urban Future 21, under the chairmanship of Sir Peter Hall and Ulrich Pfeiffer (2000). This is an important and stimulating document about the future of urbanization which academics interested in interdisciplinary research should take note of. It has three related aims:

- $\quad$ to describe the urban world in global terms;

- to establish where cities will be in 25 years time, if present trends continue; and

- to prescribe what ought to be done by whom, so that these trends may be 'bent' in future to achieve more positive outcomes.

More than ever before, cities (and researchers) ought to learn form each other. Hall and Pfeiffer (2000) define three broad categories of cities: hypergrowth cities, dynamic cities and mature developed cites. The authors then undertake a form of analysis of cities within these three groups. They first describe the future of each group based upon present trends, and subsequently prescribe optimum choices, based on intervention and 'best practice'. It is in the challenges which these kinds of cities present that interdisciplinary research must play a pivotal role.

The Berlin Declaration on the Urban Future was adopted by all delegates at the conference. The following 19 actions were identified in the declaration as being the most urgent (the last five link directly to our case study):

1. Cities should, in co-operation with other levels of government, provide incentives, regulations and benchmarks which will encourage the private sector to think globally, act locally and reach out to the poor in a non-discriminatory manner.

2. National governments should give high priority to their urban development policies in the framework of national and regional policies.

3. National and regional governments should ensure that cities have sufficient power and resources to carry out their functions and responsibilities.

4. Cities should establish forums, bilateral and multilateral partnerships to facilitate networking, mutual help and faster dissemination of best practices.

5. Non-governmental organisations and community-based organisations should be empowered to participate fully in equitable and sustainable development.

6. The private sector - local, national and international - should mobilise financial instruments and investments in a manner that promotes sustainable urban development.

7. Cities should strive to promote local economic development, including recognising the role of the informal sector and integrating the informal into the formal economy.

8. Cities should adopt social policies and measures which will lead to the reduction of violence and crime.

9. Cities should embrace information and communication technologies and promote the lifelong education of all their citizens to become learning cities and to achieve global competitiveness.

10. Cities should promote the use of environmentally friendly technologies and materials, including renewable sources of energy and higher efficiency in the use of natural resources. 
11. Cities should attempt to achieve a good balance between the natural and built environment and should take action to reduce air, water, land and noise pollution, thereby enhancing the citizens' quality of life.

12. Cities should, where appropriate, consider accepting and integrating informal settlements into the existing urban structure and social life.

13. Cities should promote the development of an appropriate integrated public transport system which is fast, safe, accessible and affordable; better management in the use of the private car; and encourage the use of environmentally friendly means of transport.

14. The World Bank, the UN Development Programme, the UN Centre of Human Settlement, other international agencies and bilateral donors should intensify their co-operation with cities, non-governmental organisations, and community-based organisations in the fields of housing, urban development and poverty alleviation.

15. Cities and other levels of government should adopt effective urban policies and planning processes which integrate the social, economic, environmental and spatial aspects of development, recognising the interdependence between the city and the region and between the urban and rural areas.

16. Cities should govern themselves and order their relations with all their citizens without discrimination, in accordance with the principles of democracy and good governance, with special outreach to women, the youth and minorities.

17. Cities should strive to alleviate poverty and meet the basic needs of their citizens by promoting economic opportunity and enabling community action.

18. Cities should adopt appropriate land use planning and implementation measures with a view to promoting vibrant economies, functioning land markets, affordable housing and suitable infrastructure.

19. Cities should conserve their historical heritage and aspire to become beautiful places where art, culture, architecture and landscape bring joy and inspiration to the citizens (Berlin Declaration, 2000).

We are entering the urban millennium. Cities, always the engines of economic growth and incubators of civilisation, today are beset by tremendous challenges. We believe that if we harness the positive forces of interdisciplinary research and education, as well as the concepts of sustainable development, globalisation, information technology, democracy and good governance, the empowerment of minority groups and civil society, we can institute cities of security, prosperity and social justice. We, as scientists at universities, must do some serious selfinvestigation to demonstrate and confirm our continuing relevance in this regard. A Stellenbosch/Bordeaux research group, therefore, has taken the "Berlin challenge" as a point of departure for launching an interdisciplinary global programme.

\section{A CASE STUDY: URBANISATION, LOCAL GOVERNMENT AND CITIZENSHIP IN AFRICA AND EUROPE}

The International Scientific Co-operation Programme (PICS) on "Urbanisation, local government and citizenship: a comparative analysis of selected African and European cities" is a joint research programme of the University of Stellenbosch, South Africa, and the Centre for African Studies in Bordeaux, France. This is an international and interdisciplinary research initiative designed to promote co-operation between researchers from different countries and disciplines. Co-operation 
revolves around the development of comparative perspectives relating to similar research interests of an urban nature. The initiative was launched by Prof. Simon Bekker of the University of Stellenbosch in South Africa and Prof. Dominique Darbon in Bordeaux. Researchers collaborating in the initiative reside in France, Gabon, Togo, Senegal and South Africa. Two workshops have already taken place: in Stellenbosch in June 2001, and in Bordeaux in November 2001 (See www.sun.ac.za/sociology/pics/).

The six cities that will be compared are Cape Town, Johannesburg, Dakar, Lomé, Libreville and Bordeaux. Research in these cities is currently being undertaken by researchers attached to various institutions and disciplines. The following participants represent some of the disciplines on the interdisciplinary team: Simon Bekker and Gary Eva (Sociology, University of Stellenbosch); Izak van der Merwe (Geography, University of Stellenbosch); Alain Dubresson (Geography, Paris); Anacle Bissielo (Sociology, Omar Bongo University, Gabon); Michel Cahen (History, Bordeaux); Robert Danioue (Political Studies, Lomé, Togo); Alain Durand-Lasserve (Development Studies, Paris); Véronique Faure (Anthropology, Bordeaux); Pieter Kok (Demography, HSRC) and Lusuko Mdunyelwa (Public Administrator, City of Cape Town).

The urban dynamics in the respective cities will be compared in the light of three research questions related to the Berlin declaration on Urban 21 (Eva, 2001):

(i) How does citizen participation influence the creation of local identity and city life? Research undertaken during the 1990s in both Africa and Europe points to the increasing importance that local life and local ties have for the identities of urban dwellers. This finding underlines the importance of citizen participation in urban government. In particular, where national identities are weak and national citizenship incoherent, the nature and extent of involvement in public affairs at local urban level may play a critical role in developing civil society. Research focuses on the extent to which old and new urban dwellers derive meaning from city life and construct shared loyalty in being members of their cities or localities within their cities.

(ii) What is the nature and extent of migration and its effect on the delivery of urban infrastructure? City governments are partially responsible for services such as housing, water, sanitation, electricity and transport. Their provision influences decisions taken by households intending to migrate. In particular, their provision deeply influences the migration choices of poor households who have little hope of finding regular employment in their destination areas. In short, interaction between migration and urban infrastructural provision is critical to urban planning. The research focuses on the relationship between migration streams (rural-urban and intra-urban), on the one hand, and the urban labour market together with urban infrastructural provision, on the other.

(iii) How do city governments use service delivery to address urban problems? Municipalities are being required not just to address service delivery issues, but to tackle poverty, social exclusion, economic development, safety and the environment. As global and societal problems become more complex, it becomes apparent that these problems can no longer be solved by a single organisation and within one knowledge field. New arrangements for urban management, marked by partnership and networks, now point the way forward. The research focuses both on more traditional forms of service delivery as well as on innovative methods.

Two types of outcomes will be of significant applied value. In the first place, comparisons of methodologies and research methods used in the different research environments will be of value in building capacity for further interdisciplinary research. In the second place, comparisons of both 
policies and practices in place in the six cities will be of value to each city and its local government in particular. The three-year programme will also culminate in a series of academic publications that will focus on comparative results. An exchange of graduate students is in operation and several doctoral students are engaged in research work both in France and South Africa.

\section{LESSONS FOR INTERDISCIPLINARY RESEARCH ON URBANISATION}

A major question addressed during workshop discussions was that of coherence (Eva, 2001). This raised the issues of shared conceptual frameworks and common methodologies. To what extent should the networks of researchers attempt to reach agreement on both the 'how' and the 'what' of city comparisons, and to what extent ought they to interact in an eclectic manner? A second major question related to the cities which would be selected and the criteria according to which this would be done. The need to establish networks, as well as to address resource imbalances in Europe, South Africa and the rest of Africa, was kept in mind.

Lessons drawn to date from our experiences within this programme may be summarised as follows (Eva, 2001):

A balance needs to be drawn between clarity of definition regarding the research topic and openness to a range of conceptual and methodological themes. Clarity of definition enables focus, but pre-empts inputs from a range of possible contributors and disciplines. Time is needed to work out the differences and to build trust.

A balance needs to be achieved between conceptual clarity and conceptual eclecticism. Efforts to tie researchers to a strictly defined research framework may turn out to be an unachievable objective. Focus on some central questions and shared themes relating to substantive areas of research may be a more productive way of proceeding. Conceptual clarity can then arise through a debate across paradigms as empirical research emerges.

Any interdisciplinary research inevitably entails a range of methodologies. Attempts to impose a common methodological grid can lead to rigidity and conflict. Focus on some central question and openness to a range of methodologies can lead to interesting synergies between qualitative and quantitative methods.

Inter-disciplinary work may lead to a lack of theoretical coherence and substantive focus. It can also enrich a study if there is a pursuit of common questions, with light being thrown on subjects from a number of perspectives. The danger of disciplinary divisions and of the increase in conceptual incoherence should be overcome by co-ordinating structures such as plenary seminars, workshops and conferences held at regular intervals and by creating a website.

Traditions of research and publication can differ between individual researchers, their disciplines and specific studies. There is a strong drive for research in South Africa to be policy relevant. This is not the case, it seems, in France where researchers have a more pure academic motive. This can lead to differences in the way research questions are posed, the way interaction with policy-makers is conducted and the way in which the expected results are published.

In comparative studies across countries it is important to build local research bases in the form of networks, partnerships or loosely organised teams. Furthermore, inequalities exist in the resource bases in Europe, South African and West Africa. Enormous sensitivity and a spirit of mutual respect and trust are needed to ensure that these imbalances do not lead to dominance by researchers from more resource-endowed countries over those from less endowed countries. 


\section{CONCLUSION}

Perhaps the best way to conclude this paper is to present a concise example drawn from our preliminary brainstorming workshops within the PICS programme. The example underlines important differences in conceptualisation both between disciplines as well as between intellectual traditions.

The notion of 'urban' is fundamental to any study of urbanisation. In South Africa, at least, the definition of what is urban and what is rural remains blurred. The central government provides a uniform classification system for the country's metropolitan areas, cities and towns (Ministry of the Office of the President, 1995). Anthropologists, however, have pointed out that rural migrants recently taking up residence in South African cities "talk about themselves institutionally as being a piece of rural society. Informal settlements are seen by their inhabitants as places where people rely on each other ... but not as part of the city" (Cross, 2000: 30). In short, one group of researchers seek a systematic administrative definition of 'urban'; others seek definitions that are meaningful to the residents themselves. This vital difference in conceptual approaches is also found in traditions that have grown up in the Anglophone and Francophone intellectual communities. The meaning of the term territory, in French territoire - a fundamental notion in the study of urbanisation - is understood by French geographers as "experienced space" and has been defined as "the result of the projection of an identity on a space" (Dupont \& Landy, 2001), whilst it is understood in a more objective spatial sense in most Anglophone social science disciplines. This example illustrates both the need for continual conceptual and theoretical interrogation and the promise of valuable new insights that may flow from interdisciplinary and international research co-operation.

Hybrid academic problems are focal points where disciplinary worlds intersect. In this process disciplinary loyalties are important, but should not undermine interdisciplinary approaches where they are appropriate and needed (Weingart \& Stehr, 2000). Urban academic researchers should perhaps concentrate more at this stage on problems and less on disciplines. Effective interdisciplinary activity grows out of established disciplinary research. Despite the hesitation of some scientists to engage in interdisciplinary research, the nature of the complex social challenges we face has given rise to an urgent need to ensure that interdisciplinary research can also prosper in Social Work as a bridging scientific discipline.

\section{BIBLIOGRAPHY}

CARUSO, D \& RHOTEN, D 2001. Lead, follow, get out of the way - sidestepping the barriers to effective practice of interdisciplinarity. The Hybrid Vigor Institute. [http://hybridvigor.org]

CROSS, C 2000. In: "Proceedings of a graduate workshop on internal migration". Occasional Paper no 11. Department of Sociology, University of Stellenbosch.

DUPONT, V \& LANDY, F 2001. "Segregation et territoire. De quoi parle-t-on?" Paper read at an international conference: Espaces, territories et identities en Afrique du Sud et en Inde. Paris.

EVA, G (ed) 2001. Proceedings of a Workshop on City Comparison - International Scientific Cooperation Programme (PICS). Occasional Paper, no 12. Department of Sociology, University of Stellenbosch.

HALL, P \& PHEIFFER, U (eds) 2000. Urban Future 21: A global agenda for twenty-first century cities. E\&FN Spon, Londen.

JOHNSTON, RJ (ed) 2000. The dictionary of Human Geography. Oxford: Blackwell. 
KUPER, A \& KUPER, J 1996. The Social Science Encyclopedia. London: Routledge.

MINISTRY IN THE OFFICE OF THE PRESIDENT 1995: "Urban Development Strategy of the Government of National Unity", Government Gazette vol 365, no 16679. Pretoria: Government Printers.

NATIONAL RESEARCH FOUNDATION 2002: Guide to research support 2003 - NRF Focus Areas. [http://www.nrf.ac.za/funding/guide/index.stm]

PELLMAR, TC \& EISENBERG, L 2000. Bridging disciplines in the brain, behavioural and clinical science. Washington: National Academy Press.

[http://books.nap.edu/html/bridgingdisciplines]

WEINGART, P \& STEHR, N 2000. Practising interdisciplinarity. Toronto: University of Toronto Press.

\section{Develop your Career inte}

Immediate vacancies throughout the UK for Qualified Social Workers...

*Visa fee re-imbursement • Immigration advice • Meet and greet service $\bullet$ Accommodation assistance • Bank account • Excellent pay $\bullet$ Free financial advice $\bullet$ Personal development fund •

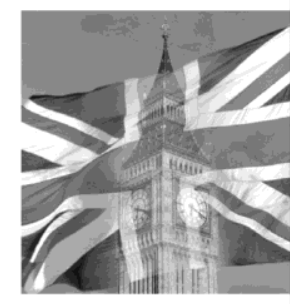

Cape Town: (021) 6805146 (012) 3624523

search our jobs @ www.social-work-solutions.co.uk E: southafrica@social-work-solutions.co.uk

*Conditions apply 'Committed to equal opportunities' 